\title{
Should I stay or should I go? Global COVID-19 pandemic influence on travel intentions of Bulgarian residents
}

\author{
Ilinka Terziyska ${ }^{1}$, and Elka Dogramadjieva ${ }^{2 *}$, \\ ${ }^{1}$ South-West University "Neofit Rilski”, Faculty of Economics, Department of Tourism, 60 Ivan \\ Mihaylov Str., 2700 Blagoevgrad, Bulgaria \\ ${ }^{2}$ Sofia University "St. Kliment Ohridski", Faculty of Geology and Geography, Geography of Tourism \\ Department, 15 Tzar Osvoboditel Blvd., 1504 Sofia, Bulgaria
}

\begin{abstract}
.
Research background: The COVID-19 pandemic brought an unparalleled global lockdown and economic paralysis, with the travel and tourism sector being among the worst affected industries worldwide. This situation has set a lot of questions regarding the future of tourism and its re-shaping into a 'new normality', among which those referring to anticipated changes in tourist demand and behavior stand out. Such questions are empirical in nature and imply conducting of studies in various contexts in order to identify customers' perceptions, attitudes, intentions, and real behavior patterns.

Purpose of the article: The paper presents results of a recent study of the influence of COVID-19 pandemic on travel intentions of Bulgarian citizens and discusses them in relation to other similar studies conducted in different countries.

Methods: The online survey covered 654 respondents and was completed in the period 9-16 April 2020, so the study results outline travel intentions at a relatively early stage of the COVID-19 crisis.

Findings \& Value added: There was a strong impact of the global pandemic on travel at the time of the research but the findings indicate less significant influence on the respondents' travel intentions for the future. While some of the outcomes support the generally expected consequences of the COVID-19 crisis, many are quite surprising and challenge existing anticipations for dramatic changes in tourist demand and behavior, at least in regards to Bulgarian customers.
\end{abstract}

Keywords: travel intentions; decision factors; COVID-19, Bulgarians

JEL Classification: $I 15 ; Z 13 ; Z 31$

\footnotetext{
*Corresponding author: elka@gea.uni-sofia.bg
} 


\section{Introduction}

The COVID-19 pandemic is among the events with the greatest global impact in the last decades [1] and while almost all spheres of life and the economy have been affected, undoubtedly one of the sectors that suffered the most was tourism. OECD estimates point to a $60 \%$ decrease in international tourism in 2020, which could reach the unprecedented $80 \%$ if the crisis continues to develop [2]. In Europe (including Bulgaria), the first cases of COVID-19 were registered in early 2020 [3], and in March strict restrictions were imposed in most countries a state of emergency was declared and travel with few exceptions was brought to a halt.

In these difficult times, research in the field of tourism is especially important to identify the economic and social consequences of the crisis and suggest the tools and strategies to tackle them [4]. A huge number of studies has already been published, and those in the field of tourism can be grouped into several main areas, united around a common theme transformation. The main fields in which the research so far has been directed are: 1) the changing needs, attitudes and behaviors of tourists; 2) changing business practices; and 3) need for better preparedness in case of a future crisis [5]. Sustainability is another running theme, with authors focusing either on crisis-induced threats on sustainability [6], or evolving trends that could actually be beneficial, such as the so-called "ecological grief" [7] or the (temporal) end of overtourism. The increasing (and innovative) use of technology is also seen as an opportunity for making tourism more sustainable [8]. There is also a call for exploring all these in the perspective of a whole new paradigm for tourism development [9].

A major part of COVID-19 related tourism studies have been focused on predicting the changes in tourist behavior and preferences. Tourism confidence has been pointed out as the main driver for industry recovery [4], with safety and sanitation measures being one of its most significant dimensions, especially when choosing accommodation [10]. In addition to perceived health risk, travel intentions in times of crisis are affected by disposable income, changes in cost of travel, and pandemic restrictions [11]. The main dimensions of the expected change are usually expressed in travelling independently or in small groups, avoidance of crowded destinations, increased requirements for food safety, more careful planning and risk management [12].

Given the specifics of different countries in terms of spread of the pandemic, local culture, life-style and attitudes of the population, changes in tourist behavior, or at least their intensity, are also expected to be different. It is therefore logical that industry-led research is usually focused on a specific market, which is also valid for the current study. While the results might not be generalizable for different settings, it is still of interest to see how they are related to findings referring to different contexts.

Bulgaria is an interesting case to study, since the COVID-19 situation there developed in a specific way that influenced the population's overall behavioral patterns and their travel intentions. The state of emergency in the country was declared quite early (on 13 March 2020) and travel was virtually prohibited for two months - people were allowed to leave their place of residence only for a serious reason. What was specific for the situation in Bulgaria at that time was the relatively low spread of the disease - in contrast to other European countries, the daily cases rarely exceeded 30 persons per day, or about 4 persons per 1 million of the population [13]. The low level of infection until early July 2020 placed Bulgaria among those countries that were best coping with the first wave of the pandemic [13]. The economic consequences of the lockdown posed serious challenges, with a lot of closed businesses and more than 170000 people who lost their jobs from March to June 2020 [14]. Yet, the scale of the economic crisis was lower than expected [15]. Meanwhile, results of a nationally representative survey conducted in early June 2020 indicated a high level of skepticism 
among Bulgarians regarding the coronavirus, with over $23 \%$ of the respondents considering it did not exist but was a global fraud, and $21 \%$ stating uncertainty on the question [16].

This paper presents results of a study that explored the travel intentions of Bulgarians in the condition of a still unfolding pandemic in April 2020. Unlike most recent studies in academic literature, which are conceptual and focus on new paradigms, this one is industrydriven and aims to identify immediate economic effects of the COVID-19 crisis on Bulgarian citizens and their travel intentions, as well as the main decision-making factors influencing travel cancellation / postponement and resumption for this specific market.

\section{Methods}

The study explored COVID-19 induced changes in travel and future travel intentions of Bulgarian residents. It referred to both domestic and outbound trips, as well as to leisure and business trips with at least one night spent.

Three main research questions underlaid the analysis: 1) what was the coronavirus crisis impact on people's jobs and income at the time of study and what was the expected strength of these effects in the future; 2) to what extent were Bulgarians affected by the COVID-19 lockdown in terms of cancelled / postponed trips and which were the main reasons for travel cancellation / postponement at the time of study; 3) what travel intentions people had for the post-lockdown period and which factors would influence their decision to travel. The study encompassed other questions of interest concerning expected changes in tourist behavior in terms of number and duration of trips, willingness to spend, use of intermediaries, reservation period, preferred destinations and activities, etc., but these were not included in the current analysis due to the paper size restrictions.

The online survey was conducted in the period 9-16 April 2020, so the findings outlined respondents' travel intentions at an early stage of the COVID-19 crisis, right in the middle of the lockdown period that in Bulgaria lasted from 13 March to 13 May 2020. Snowball sampling was applied as a technique, since the survey was distributed through Facebook. Besides the authors' personal accounts, several Facebook groups that provided access to a large audience of potential respondents with various social and demographic characteristics were used. The survey was completed by a total of 676 respondents of which 22 appeared to be Bulgarians living abroad. Since all consumption is location and time bound [17] and country-specific context of travel intentions and tourist behavior is important, the latter group was excluded from data processing. Thus, 654 valid surveys filled by respondents who live in Bulgaria were subjected to analysis.

The study sample included people from different parts of the country, with the greatest share of those living in the capital city of Sofia (55\%). Female respondents strongly dominated over male respondents ( $76 \%$ vs. $24 \%$ ), which could be explained by the generally higher willingness of women to participate in surveys [18]. Respondent groups in terms of age, employment, sphere of activity, living standard, relationship with a partner, presence of a child / children, etc. were represented in reasonable proportions corresponding to the profile of Bulgarian travelers. Various social and demographic categories allowed for more detailed breakdowns and in-depth analysis of the results, which might be of specific research and practical interest but were kept to a minimum in order to meet the paper size restrictions.

Close-ended questions were coded and subjected to descriptive data analysis using SPSS software. In particular cases, inferential statistics was applied. The chi-square test of independence was used to find relationship between variables in multiple-response sets, while the Mann-Whitney and Kruskal-Wallis tests verified differences in means derived from 5-point scale questions. Statistical significance was calculated at the 0,05 level. 


\section{Results and discussion}

\subsection{Impact of the COVID-19 crisis on financial wellbeing and travel at the time of study}

\subsubsection{Current and expected COVID-19 crisis impact on employment and income}

At the time of study, the COVID-19 crisis had somehow affected employment and income of $76 \%$ of the respondents, with $17 \%$ of them assessing the impacts as considerable and $21 \%$ as very strong (Fig. 1). People expected effects of the crisis to intensify in the future, so that $89 \%$ would be affected to some extent, with those likely to experience considerable and very strong impacts accounting to $21 \%$ and $25 \%$ respectively.

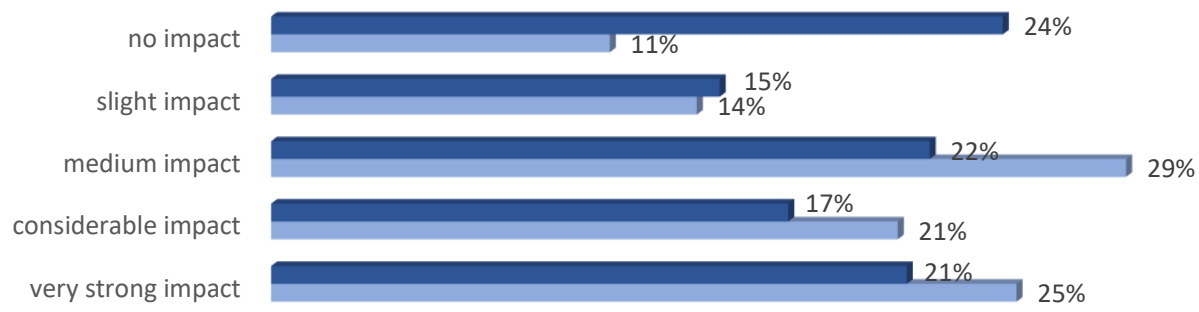

- Impact of the Covid-19 crisis on employment and income at the time of study

Expected impact of the Covid-19 crisis on employment and income in the near future

Fig. 1. Current and expected COVID-19 crisis impact on employment and income at the time of study - share of respondents.

Average scores on a 5-point scale (Fig. 2) revealed a moderate manifestation of the corona crisis effects at the time of study $(2,96)$ and increased expected strength of impacts in the future, though the situation was not anticipated to get dramatically worse $(3,34)$.

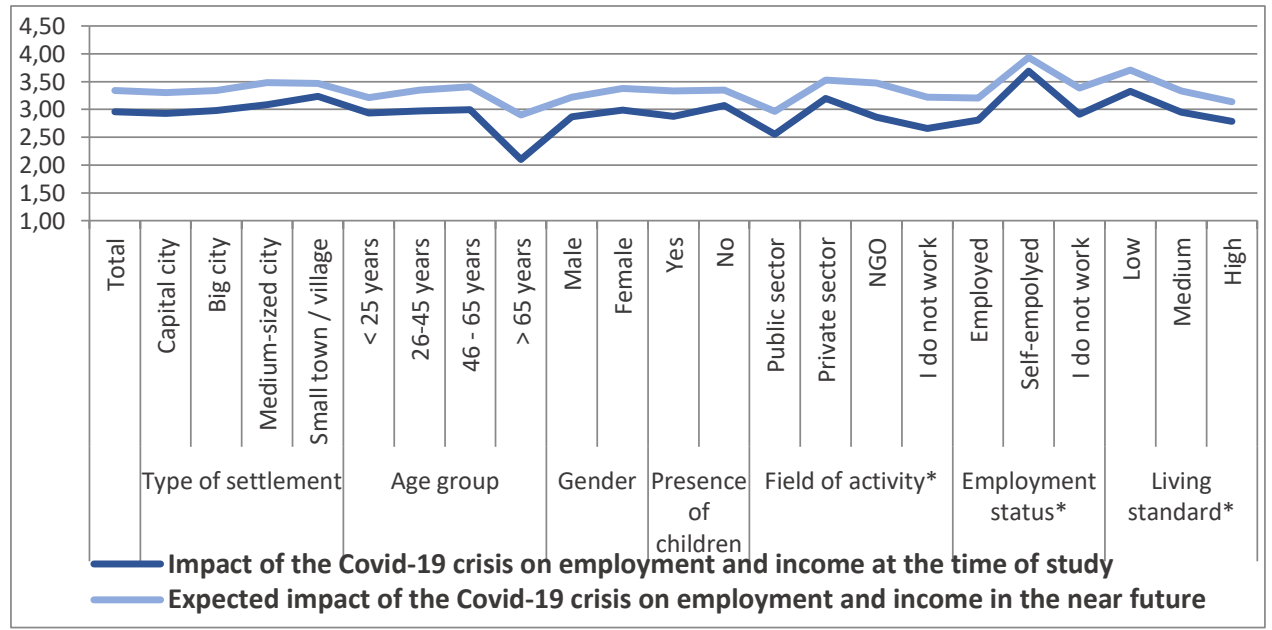

Fig. 2. Current and expected COVID-19 crisis impact on employment and income at the time of study - means by groups of respondents on a 5 -grade scale $(*$ means significantly different at $p<0,05)$. 
Breakdowns by groups of respondents indicated stronger current and expected future effects of the crisis in smaller settlements; a significantly higher degree of manifestation in the private sector than in the public sector, as well as among the self-employed respondents. Logically, the strength of the crisis impact was inversely proportional to the respondents' living standard, while COVID-19 induced changes in employment and income were least pronounced in the oldest age group (65+) that consisted predominantly of retired people.

\subsubsection{Cancelled / postponed trips at the time of study}

At the time of study, more than half of the respondents had already cancelled or postponed trips due to the COVID-19 crisis, about 1/3 had not done so (mostly because they had not planned travelling during that period), and roughly $1 / 10$ were unsure if they would take their planned trips in the future (Fig. 3). No considerable differences were outlined in this respect between domestic and international travel. Results by the purpose of visit revealed that mainly personal trips had been affected by the coronavirus $(70 \%)$ while the majority of respondents had not cancelled / postponed business trips (54\%). Less than $10 \%$ of the survey participants indicated they were still unsure if they would be able to take an earlier planned trip. A slightly higher uncertainty was registered with reference to travel abroad and leisure travel vs. domestic and business trips.

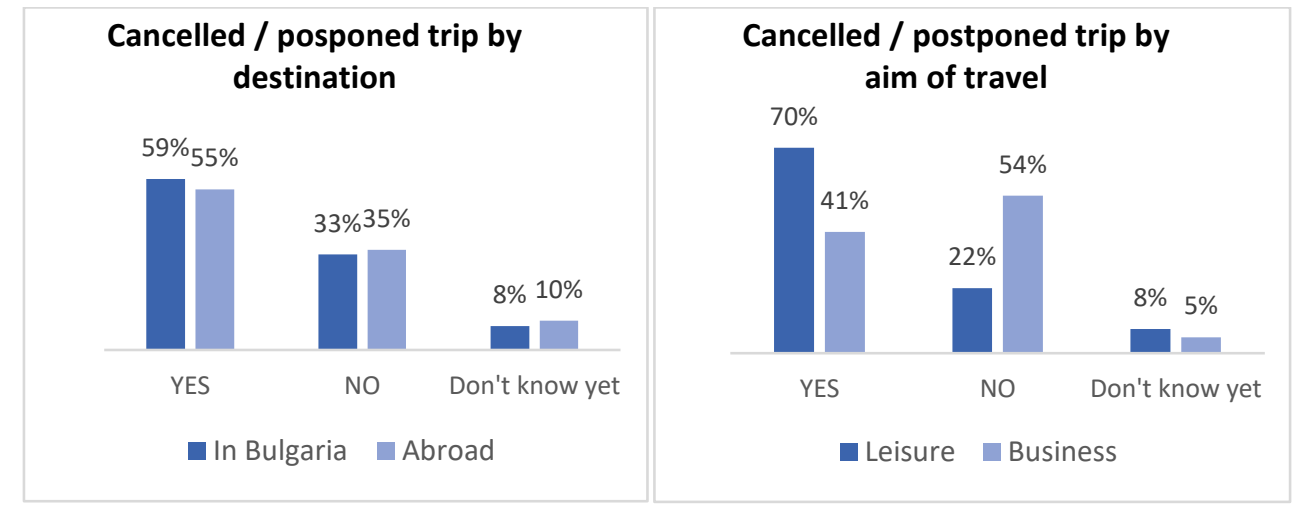

Fig. 3. Due to the COVID-19 crisis, did you personally have to cancel or postpone a planned trip with at least one night? - share of respondents.

\subsubsection{Reasons for COVID-19 induced travel cancellation / postponement}

Cancelled / postponed travel was definitely most affected by official restrictions that determined the decision of $75 \%$ of the respondents (Table 1). The second most important factor was also a 'prohibitive' one - cancellation of planned events that was mentioned by $45 \%$ of the respondents. Somewhat surprisingly, fear of infection occupied the third position among all factors enumerated in the questionnaire, pointed by only $36 \%$ of the respondents, followed by overall uncertainty about the future $(23 \%)$. The study participants were much lower affected by other constraints such as lack of convenient transportation (16\%), possible logistical disorders (14\%), and even financial difficulties (13\%). The latter reflected the early stage of the study, when the effects of the crisis on income had not been strongly felt yet. At a later stage, a change in this respect could be expected, since the retention of personal income was pointed as a number-one factor that would influence the decision to travel after the crisis (see Table 2). 
Table 1. In case you have cancelled / postponed a trip, which of the following options influenced your decision? - share of respondents.

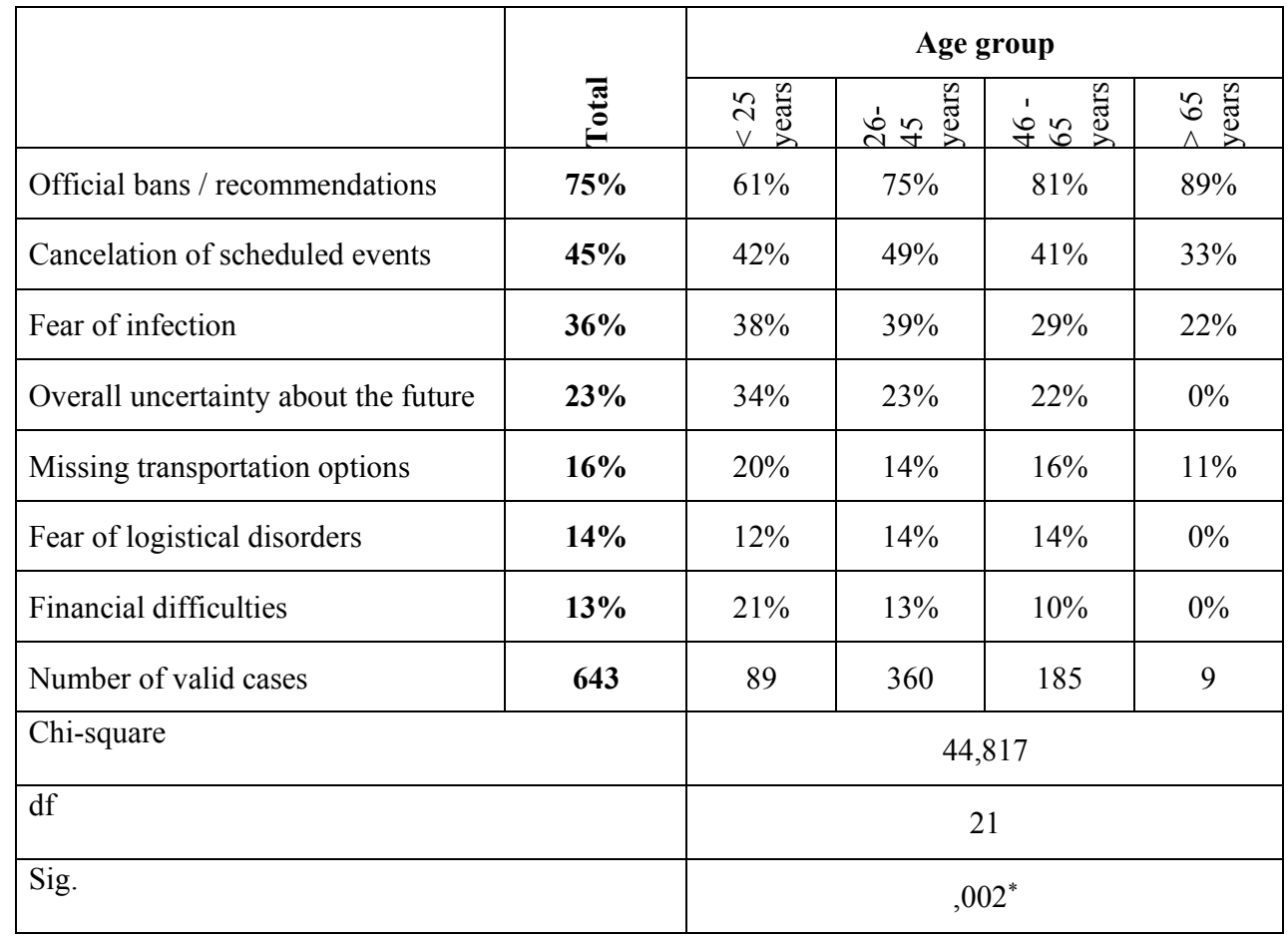

There are statistically significant differences by age groups (Table 1) indicating that formal prohibitions and recommendations were increasingly important for older respondents. On the other hand, fear of infection and overall uncertainty about the future, as well as financial difficulties, appeared more popular as decision-making factors among younger generations. Such a result, particularly regarding the fear of infection, is confirmed by another study in Bulgaria [19] and corresponds to a similar observation of a greater concern over war, conflict and security threats among the Gen $\mathrm{Y}$ and $\mathrm{Z}$ cohort in developed economies [8]. It rises a suggestion that younger people would be more worried, respectively more demanding, in relation to those elements of the tourist offer that refer to ensuring safety - a fact that should be borne in mind by the business when providing tourist services to Bulgarian customers. The relatively lower level of fear of infection among elderly people (who are one of the atrisk groups) might also be attributed to the so-called maladaptive coping response, defined as a personal strategy of reducing fear without actually trying to avoid risky or dangerous situations/behavior [20].

\subsection{Travel intentions after the COVID-19 lockdown}

\subsubsection{Intentions to take a trip after the COVID-19 lockdown}

Almost $90 \%$ of the respondents stated they would take a trip by the end of 2020 , with $70 \%$ intending to do so in the first months when travel is allowed - in the spring / summer of 2020 (Fig. 6). Early travel would be primarily domestic (70\%) and with personal aim (68\%), which is quite in line with expert predictions for the USA and Middle East markets [21, 22], as well as with the results of another study on the Bulgarian market [19]. Yet, our survey found that 
$55 \%$ of the respondents intended to travel abroad by the end of 2020 , with $26 \%$ expecting to do so quite early - during the spring/summer season. Such findings sounded rather surprising at the time of study, in the midst of the lockdown period, but proved to be right in the summer when huge queues of Bulgarians wishing to go on a holiday in Greece appeared at the border checkpoints [23], and were also confirmed by another survey conducted in early July 2020, indicating that "the pandemic has not had much of an impact on the choice of eSky users in Bulgaria" and "despite the pandemic, respondents' travel intentions and preferences remained unchanged" [24].

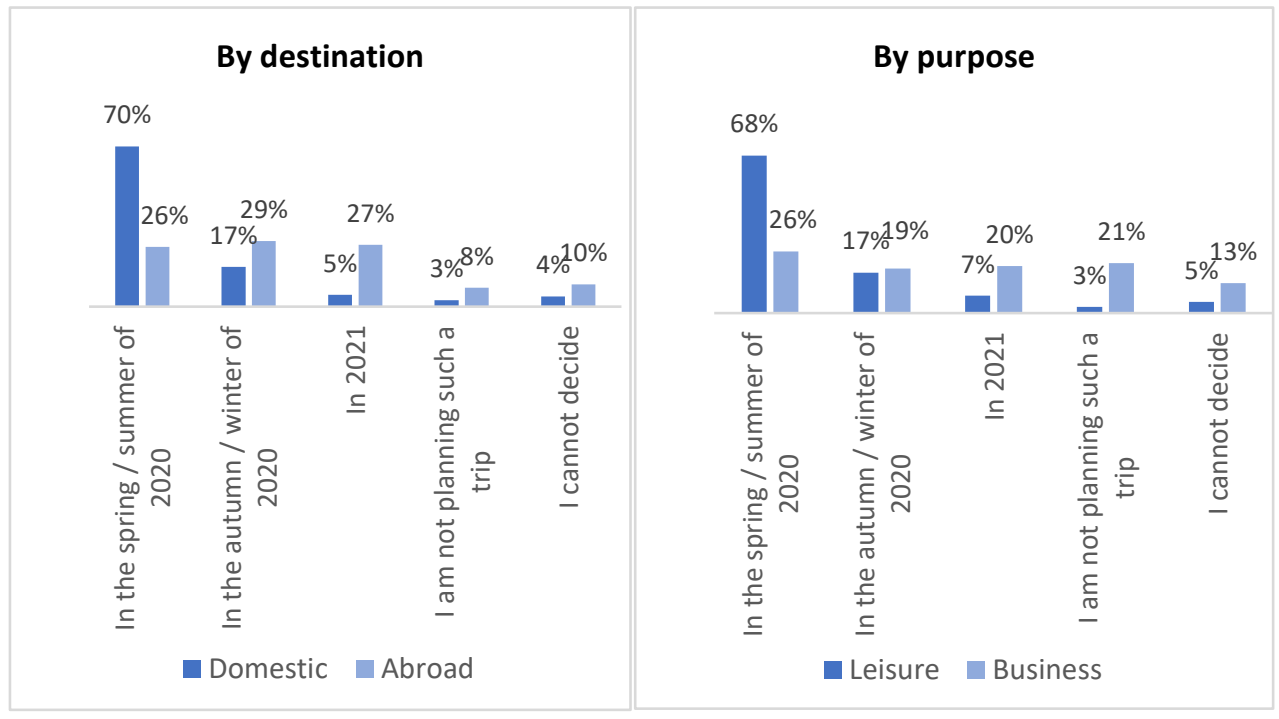

Fig. 6. When do you think you will take your first trip after the COVID-19 lockdown is lifted? - share of respondents.

Answers to the additional question "What kind of trips would you take as a priority after the end of the COVID-19 lockdown?" confirmed Bulgaria as the first choice of destination and also revealed that leisure trips (61\%) and trips for visiting friends and relatives $(57 \%)$ strongly dominated travel intentions, while business or other personal-aim trips would be a priority for less than $1 / 3$ of the respondents (Fig. 7). At the same time, a considerable part of the survey participants pointed out travelling abroad as their priority (38\%), and only $3 \%$ were adamant that they would not undertake any travel in the foreseeable future.

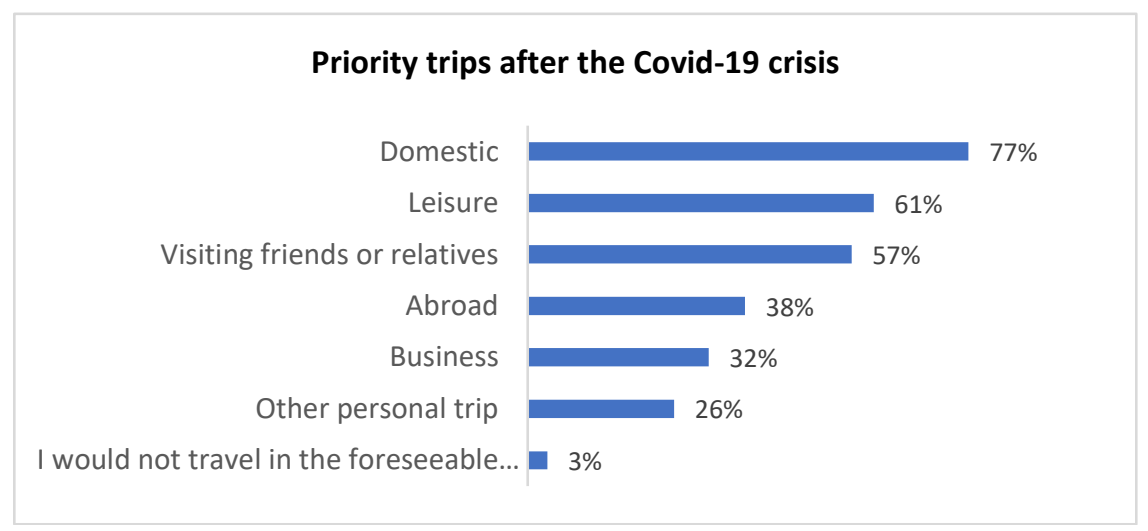

Fig. 7. What trips would you take as a priority after the end of the COVID-19 lockdown? - share of respondents. 


\subsubsection{Factors influencing travel intentions}

The respondents had to score on a 5-grade scale how strong their travel intentions would be influenced by each of the eleven potential factors enumerated in the questionnaire (Table 2). The leading one among them appeared to be the level of income $(3,68)$ followed by the reopening of flights $(3,49)$ and overall economic stabilization $(3,31)$. Study findings also indicated that resumption of cultural events $(3,25)$ would be of higher importance for people to start travelling again than resumption of business and sport events $(2,87$ and 2,54 respectively). Quite surprisingly, travel intentions appeared to be loosely linked to invention of vaccine / drug against COVID-19 $(2,91)$, which probably reflected the lower extent to which Bulgaria was affected by the disease at the time of study as well as the fact that a large proportion of the Bulgarian population is not even now convinced that the coronavirus threat is real. The bottom of the travel recovery factors ranking was occupied by the travel agencies activity restoration $(2,53)$ and the possibility to use a voucher for an already paid but unrealized trip $(2,43)$.

Statistically significant differences were found in regards to gender and age, showing that younger travelers would be more affected by overall economic stabilization and resumption of cultural events; people between 26 and 65 years of age would be stronger influenced by the resumption of business events, while travelers over the age of 65 would be more affected by the resumption of tour operators and much lower influenced by the operation of online booking platforms. It is also interesting that most of the listed factors (except inventing a vaccine and resumption of sport events) would have considerably weaker impact on men than on women.

Table 2. Factors influencing travel intentions by age group and gender - means on a 5-grade scale $(*$ means significantly different at $\mathrm{p}<0,05)$

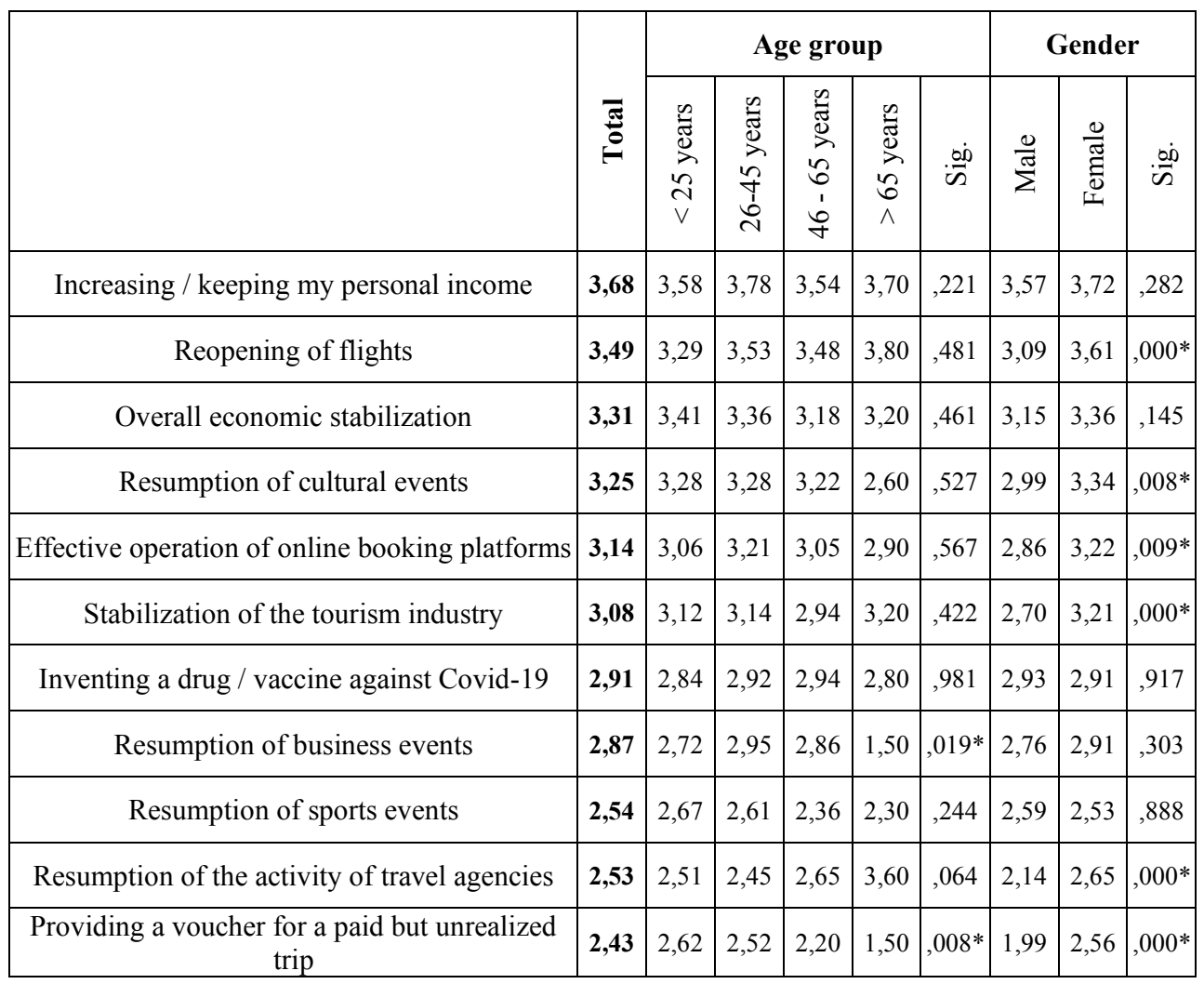




\section{Conclusions}

The effects of the COVID-19 crisis have both economic and psychological aspects and are complemented by a high degree of uncertainty about the future development of the pandemic and its impact on lifestyle and particularly, on tourist travel. This study has shown that in the early stage of the coronavirus crisis, it had already had a negative impact on jobs and income of a significant part of the Bulgarian population, and the effect was expected to intensify in the future. At the time of study more than half of the respondents had already canceled or postponed travel - either in the country or abroad - due to the COVID-19 outbreak. However, the fear of infection ranked third among the most important reasons for canceling a trip, mentioned by just over $1 / 3$ of the respondents, while 'prohibitive' factors such as official travel bans and canceled events played a major role. The study findings have not contested the growing importance of health safety and hygiene measures outlined by other surveys [10, 19], but at the same time emphasized that, at least as far as Bulgarians are concerned, the restrictive measures imposed both within the country and abroad, together with economic circumstances and the level of personal income, would most strongly determine travel in the near future.

According to the study results nearly $90 \%$ of the respondents would travel by the end of 2020 , and $70 \%$ would do so in the first months when this is allowed - in the spring / summer of 2020. Early travel would be primarily domestic, but more than half of the respondents intended to travel abroad by the end of 2020, and 1/4 expected to do so in the spring-summer season. Priority trips after the end of the COVID-19 crisis would be for the purpose of leisure and visiting friends and relatives (VFR).

Generally, these findings have revealed a more optimistic picture regarding travel intentions than it was expected during the lockdown period. They have challenged existing anticipations of a complete change in tourist demand and behavior but confirmed the expectations of localism and social connection (demonstrated by VFR) to be the primary factors in the early stages of tourism recovery [25].

The survey limitations refer to the non-probability sampling as well as to the period of the study conduction in the early stage of the coronavirus crisis. Therefore, the research findings should be considered with caution. Yet, they reveal travel intentions of Bulgarian residents and their willingness to resume traveling, and lay the ground for comparison with future research results that might document changing travel intentions as a reflection of the fluctuating health situation, and the expected deepening of the economic crisis.

The article is supported by a research project funded by the Sofia University "St. Kliment Ohridski" Research Fund (contract № 80-10-55/13. 04 2020). The authors are grateful for the opportunity.

\section{References}

1. He, H., Harris, L. (2020). The impact of Covid-19 pandemic on corporate social responsibility and marketing philosophy. Journal of Business Research, 116, 176-182.

2. OECD (2020). Tourism Policy Responses to the Coronavirus (COVID-19). OECD . Retrieved from: https://www.oecd.org/coronavirus/policy-responses/tourism-policyresponses-to-the-coronavirus-covid-19-6466aa20/

3. Penerliev, M., Petkov, V. (2020). Geodemographic Aspects of Covid-19. Espaço e Economia [Online], 18, https://journals.openedition.org/espacoeconomia/13444

4. Rivera, M. A. (2020). Hitting the reset button for hospitality research in times of crisis: Covid19 and beyond. International Journal of Hospitality Management, 87, 102528. 
5. Lew, A. A., Cheer, J. M., Haywood, M., Brouder, P., Salazar, N. B. (2020). Visions of travel and tourism after the global COVID-19 transformation of 2020. Tourism Geographies. 22(3), 455-466.

6. Newsome, D. (2020). The collapse of tourism and its impact on wildlife tourism destinations. Journal of Tourism Futures, Ahead-of-print.

7. Crossley, E. (2020). Ecological grief generates desire for environmental healing in tourism after COVID-19. Tourism Geographies, 22(3), 536-546.

8. Fennell, D. A. (2020). Technology and the sustainable tourist in the new age of disruption. Journal of Sustainable Tourism, Ahead-of-print.

9. Sigala, M. (2020). Tourism and COVID-19: Impacts and implications for advancing and resetting industry and research. Journal of Business Research, 117, 312-321.

10. Naumov, N., Varadzhakova, D., Naydenov, A. (2020). Sanitation and hygiene as factors for choosing a place to stay: perceptions of the Bulgarian tourists. Anatolia, Ahead-ofprint.

11. Gössling, S., Scott, D., and Hall, C. M. (2020). Pandemics, tourism and global change: a rapid assessment of COVID-19. Journal of Sustainable Tourism, Ahead-of-print.

12. Wen, J., Kozak, M., Yang, S., and Liu, F. (2020). COVID-19: potential effects on Chinese citizens' lifestyle and preferences. Tourism Review, Ahead-of-print.

13. Worldometer (2020). Coronavirus / Bulgaria. Worldometer. Retrieved from: https://www.worldometers. info/coronavirus/country/bulgaria/

14. Bulgarian Employment Agency (2020). Monthly newsletters. Ministry of Labour and Social Policy. Retrieved from: https://www.az.government.bg/bg/stats/2/

15. Nikolov, A. (2020, May 29) Which sectors in Bulgaria lost the most employees due to the crisis? (in Bulgarian). Money.bg. Retrieved from: https://money.bg/economics/koisektori-v-balgariya-osvobodiha-nay-mnogo-sluzhiteli-zaradi-krizata.html

16. Trend (2020, June). Attitudes of Bulgarians towards the coronavirus and conspiracy theories (in Bulgarian). Trend. Retrieved from: https://rctrend.bg/project

17. Sheth, J. (2020). Impact of Covid-19 on consumer behavior: Will the old habits return or die? Journal of Business Research, 117, 280-283.

18. Curtin, R., Presser, S., Singer, E. (2000). The effects of response rate changes on the index of consumer sentiment. Public Opinion Quarterly, 64, 413-428.

19. Ivanova, M., Ivanov, I. K., Ivanov, S. (2020). Travel behaviour after the pandemic: the case of Bulgaria. Anatolia, forthcoming article.

20. Wang, J., Liu-Lastres, B., Ritchie, B. W., and Mills, D. J. (2019). Travellers' selfprotections against health risks: An application of the full Protection Motivation Theory, Annals of Tourism Research, 78, 102743.

21. MMGY Global (2020, May 4). COVID-19 Travel Insight Report, 4th May 2020. Retrieved from: https:/www.mmgyglobal.com/covid-19-travel-insight-report/

22. Choufany, H. M. (2020, April 29) HVS COVID-19: Traveller and Hotel Guest Sentiment Findings Middle East. HVS. Retrieved from_https://www.hvs.com/article/8766-hvscovid-19-traveller-and-hotel-guest-sentiment-findings-middle-east

23. Mediapool (2020, June 19). Queues on the border with Greece and Romania. Mediapool. Mediapool.bg. Retrieved from: https://www.mediapool.bg/opashki-nagranitsite-s-gartsiya-i-rumaniya-news $308825 . \mathrm{html}$ 
24. TB Magazine (2020, July 15). Despite the pandemic, people are planning trips and vacations. Your business. Retrieved from: https:/www.tbmagazine.net/statia/vprekipandemiyata-khorata-planirat-ptuvaniya-i-vakancii.html

25. Peters, K., Peters, J., Peters, N. (2020). Visit People: Tourism Recovery after disaster. KPPM Strategy. Retrieved from http://kppm.com.au/wpcontent/uploads/2020/04/KPPM-Tourism-Recovery-Lit-Review-4-4-20.pdf 